\title{
La Unión Europea y Colombia. Historia y desafío ${ }^{1 /}$ The European Union and Colombia. History and challenges
}

\author{
Margarita Lillo González \\ y Antonio Santamaría García
}

Consejería de Educación de la Comunidad de Madrid y Escuela de Estudios Hispano-Americanos, CSIC

Este artículo revisa la historia y situación actual de las relaciones Unión EuropeaColombia en sus dimensiones política y económica. Analiza el modo en que la posición de la UE se ha mantenido constante en cuanto a su consideración de que los conflictos en el país andino se deben a las desigualdades y la pobreza, a pesar de las presiones de Estados Unidos, que ha defendido posturas más unilateralistas y militares al respecto, e incluso de que algunos socios comunitarios se hayan alineado con ellas. Frente a estudios anteriores se aboga explícitamente por un balance que haga hincapié en los aspectos positivos y constructivos, coherentes con los de un escenario en proceso de creación y ampliación como es el europeo, aunque sin renunciar a valorarlo con una perspectiva crítica.

Palabras ClaVes: Unión Europea; Colombia; Relaciones Internacionales; Relaciones Políticas; Relaciones Económicas; Cooperación para el Desarrollo; Historia Actual; Conflicto Social; Terrorismo; Narcotráfico; Derechos Humanos; Democracia; Educación; Siglos XX-XXI.

This article reviews the history and present situation of the relations between the European Union and Colombia in its political and economic dimensions. It analyzes the way in which the position of the EU has stayed constant as far as considering that the Colombian conflicts are caused by the inequalities and the poverty, in spite of the pressures of the United States, that have defended more unilateralist and military positions on the matter, positions with that some communitarian partners have even aligned themselves. In front of previous studies, it is pleaded explicitly for a balance that insists on the positive and constructive aspects, coherent with a scene in process of creation and extension, like the European one, although without resigning to value it from a critical perspective.

KeYwords: European Union; Colombia; International Relations; Political Relations; Economic Relations; Cooperation for the Development; Present History; Social Conflict; Terrorism; Drug Trafficking; Human Rights; Democracy; Education; 19th - 20th Centuries.

1 Este artículo tiene su origen en un informe encargado por el Centro de Estudios Para la PazFundación Hogar del Empleado, CIP-FUHEM que no se publicó. Su edición actual se realiza en el marco de un proyecto intramural especial del CSIC (PIE 200810I008, 2008-2009), y del proyecto "América, la gran frontera. Mestizajes, circulación de saberes e identidades" (HUM030, Sistema de Información Científica de Andalucía, SICA, Junta de Andalucía). Agradecemos los comentarios y sugerencias de Antonio Sanz Trillo, Justina Sarabia Viejo y de los evaluadores anónimos del Anuario de Estudios Americanos. 


\section{Introducción}

La política de la Unión Europea (UE) ha procurado tradicionalmente enfocar los problemas de Colombia y su ayuda al país sudamericano desde una perspectiva integral, enfatizando su dimensión regional y la participación de la sociedad civil. Se entiende que la violencia, el narcotráfico y sus secuelas - terrorismo, criminalidad, violaciones de los Derechos Humanos por diferentes actores fuera de la ley, pero también por parte del Estadoresponden a una situación de pobreza y desigualdades, particularmente en la propiedad de la tierra, en el acceso a los recursos y servicios y en la distribución de la riqueza. Esa situación es especialmente grave para algunas regiones y colectivos. Mujeres, niños, campesinos, sobre todo en áreas marginales, y comunidades indígenas son los más desfavorecidos.

Las relaciones entre la UE y Colombia se desarrollan en diversas esferas: en el plano bilateral, entre el gobierno y otras instituciones de ese país y los socios comunitarios; en el multilateral, dentro del marco de los acuerdos suscritos entre dicha nación y los organismos internacionales y regionales de los que forma parte -Organización de Estados Americanos (OEA), Comunidad Andina de Naciones (CAN) y Organización Mundial del Comercio (OMC) - .

En las dos esferas citadas las relaciones, ya sean económicas, políticas, de cooperación, ordinarias y extraordinarias (sobre problemas específicos), y tanto las habituales entre países y grupos de países, como las destinadas a la ayuda al desarrollo, están estrechamente vinculadas en el caso colombiano con otras encaminadas a resolver un conflicto que, por su duración, complejidad y envergadura, se ha convertido en endémico y que con el tiempo se ha unido al problema general del narcotráfico y a la lucha internacional contra él.

Las acciones de cooperación de la UE y sus miembros han intentado tradicionalmente ayudar a resolver las causas de la conflictiva situación colombiana, condicionándolas al respeto a la democracia, los Derechos Humanos y el Derecho Internacional Humanitario. Tales fundamentos, empero, se han visto obstaculizados por las dificultades para alcanzar consensos en el seno de la Unión Europea y por la preferencia que algunos de los socios comunitarios han conferido a sus relaciones con Estados Unidos y a su forma de entender los problemas de la nación andina desde hace años. Tradicionalmente Gran Bretaña ha practicado una política seguidista 
respecto a la marcada por la Administración de Washington, pero también, al menos de modo eventual, en la lucha contra el terrorismo y narcotráfico, lo han hecho los gobiernos del Partido Popular en España hasta 2004, o los de varios otros países del norte del Viejo Continente (por ejemplo Holanda) y los de Estados recientemente incorporados a la UE (verbigracia Polonia). Varios integrantes de la UE, por tanto, han defendido la tesis de que la respuesta a las luchas civiles y el conflicto armado, y al cultivo, elaboración y tráfico de drogas debe ser prioritariamente militar, tal y como ha sostenido el presidente norteamericano George W. Bush, sobre todo tras los atentados del 11 de septiembre de 2001 (11-S) contra las Torres Gemelas de Nueva York y en apoyo a la política diseñada por su homólogo colombiano Álvaro Uribe.

La política exterior de la UE no sólo se ha visto condicionada por las contradicciones y variaciones en su definición y objetivos. También han tenido un efecto poco positivo en ella los cambios en el modo de asignar los recursos, fruto de las necesidades que imponen su ampliación a los países del este europeo y de privilegiar los problemas de su periferia geográfica (Rusia, las vecinas repúblicas ex soviéticas, los Balcanes, Oriente Próximo, el Magreb), además de los obstáculos para reformar la Política Agraria Común (PAC) debido a las presiones proteccionistas de sus agricultores frente a los proyectos de liberalización comercial de la OMC, que sería la mejor concesión posible para paliar la pobreza de los países en desarrollo.

Se puede afirmar, no obstante, que la UE ha mantenido el enfoque de su política exterior, a pesar de los mencionados problemas y avatares, y que muchos de sus socios, y entre ellos las poderosas Francia y Alemania, han variado poco sus posiciones acerca de que es necesario priorizar la ayuda al desarrollo e intentar atajar las raíces de los problemas antes, o al menos a la vez, que sus consecuencias. Hay que considerar que la UE es un espacio en construcción y ampliación, y valorar positivamente la persistencia de tales posturas como signo de robustez, no sólo como síntoma de debilidad. De igual forma conviene valorar también el interés siempre manifiesto de erigirse en un contrapeso a la hegemonía mundial de Estados Unidos, aunque compatible con las relaciones de amistad, cooperación y defensa común de la democracia, la libertad y el desarrollo equilibrado de los países entre aliados tradicionales. Esas ideas, además, han recobrado fuerza a causa de las dificultades generadas por la ocupación de Irak y la necesidad que tiene el gobierno norteamericano de reforzar su apoyo internacional y de dar mayor espacio a los mecanismos de acción multilateral frente a los 
nuevos escenarios de litigio surgidos tras la Guerra Fría, el avance de la globalización y la persistente lacra del hambre, la pobreza y la enfermedad en las áreas más desfavorecidas del planeta.

Este artículo propone revisar las relaciones UE-Colombia desde las perspectivas política, comercial y de cooperación, su historia, las acciones en que se ha concretado, sus resultados y sus déficits, y todo ello vinculado a la evolución de la situación y los problemas del país andino y de la construcción europea. Se dedica particular atención, además, al modo en que han influido en tales relaciones acontecimientos relativamente reciente -el 11-S, la guerra de Irak, los éxitos y fracasos de la política antiterrorista estadounidense, de la lucha contra el narcotráfico y de las negociaciones y acuerdos en la OMC - , así como a la declaración final emanada de la cumbre de Cartagena, de febrero de 2004. Finalmente se apuntan cuáles son las perspectivas que se vislumbran y algunas conclusiones.

\section{Colombia en cifras o la realidad socioeconómica}

Colombia ocupa un puesto intermedio-alto en los índices internacionales de medición del desarrollo, ${ }^{2}$ pero en los que valoran derechos y libertades su posición empeora considerablemente. ${ }^{3}$ Según el Departamento Administrativo Nacional de Estadística (DANE) su PIB per capita real es de unos 1.800 dólares estadounidenses ${ }^{4}$ y ha experimentado recientemente fluctuaciones típicas de las situaciones de crecimiento stop-and-go que han caracterizado tradicionalmente a las economías latinoamericanas ${ }^{5}$ (en 1996

2 El Programa de Naciones Unidas para el Desarrollo (PNUD) califica a Colombia en el HDI (human development index) en la posición 73 y señala que se ha producido un empeoramiento en los últimos años. La Heritage Foundation le otorga un coeficiente intermedio en el IEF (index of economic freedom): 3,21 (la mejor puntuación es 1,00), entre las peores desde 1995 (ha llegado a alcanzar 2,91). Ver PNUD: Human development report, Oxford University Press, Oxford, 2004 (http://hdr.undp.org/reports/global/2004/, consulta octubre de 2008), y Heritage Foundation: Index of economic freedom, Wall Street Journal, New York, 2005 (http://www.heritage,org/research/ feature/index, consulta octubre de 2008).

3 La Freedom House: Freedom in the world 1995-2005, Freedom House, Boston, 2005 (http://www.freedomhouse.org/ratings/index.htm, consulta octubre de 2008), cataloga a Colombia en el IFW (index of freedom in the world) como parcialmente libre, con una puntuación de 4 en derechos y libertades civiles (la mejor calificación es 1).

4 Departamento Administrativo Nacional de Estadística (DANE): Información estadística, DANE, Santa Fe de Bogotá, 1990-2007 (www.dane.gov.co, consulta octubre de 2008).

5 Ver, por ejemplo, Santamaría García, Antonio (coord.): Las economías latinoamericanas en perspectiva histórica: monográfico de Debate y Perspectivas. Cuadernos de Historia y Ciencias Sociales, 5, Fundación Mapfre Tavera, Madrid, 2006. 
alcanzó 2.662 dólares; en 1999, por ejemplo, decreció un 4,2 por ciento, para aumentar luego entre 1,5 y 2,9 y, a partir de 2003, un 4,0). Además, aunque se ha reducido la inflación (del 16,7 por ciento en 1998 al 5,5 en 2004) la deuda externa ha aumentado considerablemente: en 2003 alcanzó 23.651.000.000 dólares, y en 2004, apenas superó los 24.000.000.000. ${ }^{6}$

Otro indicador de las dificultades económicas de Colombia es el desempleo. Según los datos ofrecidos por la Comisión Económica para América Latina y el Caribe (CEPAL), la tasa de desempleo alcanzó el 15,5 por ciento en 2004, ${ }^{7}$ aunque oficialmente se reconoce un 13,2. Además la mayoría del trabajo es poco productivo y hay gran inestabilidad laboral. Mujeres y jóvenes padecen condiciones más precarias y en el inicio del presente milenio el paro femenino ronda el 52 por ciento y entre los menores de 24 años el $34 .{ }^{8}$ Por otro lado menos de una cuarta parte de los jubilados percibe pensión. En las áreas rurales la situación es peor. Se calcula que en ellas hay un 18 por ciento de analfabetos y unos dos millones de niños sin escolarizar.'

Colombia es uno de los países del mundo con mayores desigualdades sociales. En el inicio del siglo XXI el 61 por ciento de la tierra pertenece al 0,4 por ciento de la población, aproximadamente dos tercios de sus habitantes se hallan en el umbral de la pobreza y una tercera parte por debajo de él. Las prioridades presupuestarias del programa de Seguridad Democrática del presidente Uribe han afectado negativamente a éstos y otros indicadores..$^{10}$ Se estima que un 43 por ciento de los ciudadanos carece de Seguridad Social y que la nación se halla ante un retroceso de su perfil epidemiológico y han reaparecido enfermedades como el sarampión, la malaria o el tifus. ${ }^{11}$

6 Datos de la Secretaría General de la Comunidad Andina, Santa Fe de Bogotá (http://www.comunidadandina.org/quienes/colombia.htm, consulta octubre de 2008).

7 Comisión Económica para América Latina y el Caribe (CEPAL): Panorama social de América Latina, CEPAL, Santiago de Chile, 2004, pág. 166.

8 DANE: Información estadística.

9 Ver "Análisis de coyuntura: Colombia Hoy: 1998-2002" [2003] (www.actualidadcolombiana.org/archivo/index1.htm, consulta octubre de 2008), y Comisión Colombiana de Juristas: Colombia: en contravía de las recomendaciones internacionales sobre derechos humanos. Balance de la política de seguridad democrática y la situación de los derechos humanos y el derecho humanitario (agosto 2002 a agosto 2004), Comisión Colombiana de Juristas, Santa Fe de Bogotá, 2004.

10 Contraloría General de la República: La crisis socio-económica en Colombia: la otra guerra, Contraloría General de la República, Santa Fe de Bogotá, 2004 (www.contraloriagen.gov.co, consulta octubre de 2008).

11 Quintana, Stella: "El acceso a los servicios de salud en Colombia". Cuadernos para el Debate, 1, Santa Fe de Bogotá, 2002, pags. 18-39 (www.msf.es, consulta octubre de 2008). 
La situación descrita, en franco deterioro desde hace años, tiene orígenes antiguos y es la causa de los conflictos que sufre Colombia. En las décadas de 1940 y 1950, debido al escaso control estatal en amplias zonas del territorio, y sobre todo a la violencia institucionalizada en esa época, que acabó con la vida de numerosos líderes políticos y sindicales, aparecieron los movimientos insurgentes. Gran parte de ellos han desaparecido y algunos, como el M-19, se han incorporado a la vida política del país, pero aún persisten varios muy numerosos y poderosos. Actualmente la Fuerzas Armadas Revolucionarias (FARC), y el Ejército de Liberación Nacional (ELN) son los más importantes y cuentan con unos 20.000 y 5.000 miembros respectivamente. Por otra parte, frente a ellos, como mecanismo de protección de los terratenientes, se crearon también en los años setenta facciones armadas de derecha que con el tiempo se organizaron en grupos paramilitares, integrados hoy mayoritariamente en las Autodefensas Unidas de Colombia (AUC), con aproximadamente 14.000 hombres. Las AUC han contado tradicionalmente con la colaboración o tolerancia del ejército, consecuencia de la incapacidad de éste para proporcionar seguridad en la totalidad del territorio nacional. Posteriormente todos los grupos mencionados se vincularon con el narcotráfico (el ELN en menor medida), que surgió de modo independiente, pero les brindó una sólida base de financiamiento. ${ }^{12}$

La combinación de conflicto armado, narcotráfico y pobreza, desigualdad y exclusión — problemas comunes a otros países de América Latina y del planeta - ha provocado en Colombia una situación de extrema violencia. Las evidencias son incontestables: 8.078 civiles han sido asesinados por los grupos armados sólo entre 1997 y 2003; 2.856 personas sufrieron secuestro en 2001 - lo que convierte al país andino en la nación del orbe con más delitos de este tipo-, cerca de 4.000 violaciones de los Derechos Humanos denunciadas en los inicios del nuevo milenio, o el desplazamiento forzado de más de 2.000 .000 de personas desde $1985 .{ }^{13}$ Parte

12 International Crisis Group: Las fronteras de Colombia: el eslabón débil de la política de seguridad de Uribe, International Crisis Group, Quinto y Bruselas (Informe sobre América Latina, 9), 2005, págs. 8-23 (http://www.icg.org/home/index.cfm?id=3025\&l=4, consulta octubre de 2008).

13 Datos de la Consultoría para los Derechos Humanos y el Desplazamiento (CODHES): III Seminario CODHES, CODHES, Santa Fe de Bogotá, 2005 [8-10 de noviembre] (www.codhes.org.co/ dsemanal.php?informe $=49 \&$ report $=49$, consulta octubre de 2008). Esas cifras suponen una media de 100.000 personas anuales desplazadas y la situación se ha agravado con los años. En 2002 se alcanzó el récord de 412.000 y, tras una reducción en 2003, consecuencia de la transición hacia un nuevo modelo de confrontación armada (Política de Defensa y Seguridad Democrática y Plan Patriota), en 2004 volvió a aumentar hasta 287.581. Ver CODHES: "Desplazados en el limbo", Boletín, 56, Santa Fe de Bogotá, 2005, págs. 1-7 (http://www.codhes.org.co/dbreves2.php?breve=306, consulta octubre de 2008). 
de esos desplazamientos son causa del conflicto - se calcula que los insurgentes poseen más de 3.000.000 hectáreas de tierra—, pero a ello se ha unido recientemente el efecto de las fumigaciones de los cultivos de drogas. ${ }^{14}$

\section{Colombia y Unión Europea: política, comercio y cooperación. Las relaciones en la década de 1990}

Las relaciones UE-Colombia tienen una larga tradición y se han mantenido dentro de un marco que prioriza el compromiso por la solución negociada a un conflicto que se entiende causado por una situación de pobreza y desigualdad y que es preciso mitigar. Por tanto se han desarrollado de modo coherente con la estrategia de definir un ideario en la política exterior europea que privilegie la ayuda al crecimiento equilibrado y sostenible de los países, fomente la democracia, los Derechos Humanos y la concordia universal, y sirva como contrapeso a la hegemonía de Estados Unidos, que con el paso del tiempo ha radicalizado sus posturas unilateralistas y beligerantes, pero también colabore en la defensa de esos mismos valores, tradicionalmente defendidos por dicha nación, no obstante las diferencias en los métodos, y por diversos organismos internacionales, oficiales y no gubernamentales (especialmente por la Organización de Naciones Unidas, ONU). En ese sentido se ha intentado potenciar la consolidación de la sociedad civil, el avance de los procesos de integración regional — de la Comunidad Andina en el caso que nos ocupa - y la participación de ambos en la resolución de los mencionados problemas.

La política de paz en Colombia, ligada desde la década de 1980 a la necesidad de reforma del régimen político, se concretó en 1991 en una nueva Constitución que intentó modificar la situación de desigualdad y violencia con importantes avances en el Estado de Derecho y dando más participación a formaciones independientes, regionales y locales. Sin embargo la

14 Ver Comisión Colombiana de Juristas: Colombia: en contravía, págs. 11-17, y Delegación de la Comisión Europea para Colombia y Ecuador (DELCOLEC): La Unión Europea y Colombia, DELCOLEC, Santa Fe de Bogotá, 2004 (http://www.delcol.cec.eu.int/es/novedades/Separata\% 20de\%20cooperación.pdf, consulta octubre de 2008), Evolución de las relaciones comerciales Colombia-Unión Europea, DELCOLEC, 2004 (http://www.delcol.cec.eu.int/es/novedades/Separata\% 20de\%20comercio\%202004.pdf, consulta octubre de 2008), y "Colombia/relaciones" [2004] (http://www.delcol.cec.eu.int/es/ue_colombia/relaciones_economicas.htm, consulta octubre de 2008), y sobre el conflicto armado, sus orígenes y evolución, González Bustelo, Mabel y Aristizábal, José: Colombia. La guerra que no para, Ayuntamiento de Córdoba, Córdoba, 2003. 
carta magna no ha podido atajar los altos niveles de impunidad y corrupción en el país. En 2004 el índice de percepción de la corrupción situaba a la nación americana en el puesto 60 entre las 146 consideradas..$^{15}$

Los avances en las relaciones de la UE con los países del área andina motivaron que en 1993 la Comisión Europea abriese una delegación diplomática para Colombia y Ecuador en Santa Fe de Bogotá (DELCOLEC). El propósito de esa embajada, además de reforzar dichas relaciones, es prestar ayuda a la población desplazada por la violencia y a los damnificados por desastres naturales a través de la Oficina de Ayuda Humanitaria (ECHO). En 1995 Colombia intervino, además, en el Diálogo Especializado sobre Drogas UE-CAN (Comunidad Andina), firmó un acuerdo sobre precursores y sustancias químicas usadas para producir narcóticos ilícitos (que entró en vigor en 1997), y recibió una dotación de 85.000.000 de euros entre los años 1995 y 2000 para asistencia técnica, económica y financiera. ${ }^{16}$

El presidente Andrés Pastrana lideró a partir de 1999 un proceso de paz mediante el anuncio del Plan Colombia, auspiciado por su homólogo estadounidense entonces, Bill Clinton. El proyecto reforzaba la participación en la pacificación de la comunidad internacional, alejada durante el gobierno de Ernesto Samper — debido a las acusaciones de que fue objeto de haber sido financiado por el narcotráfico_- e impulsaba el acercamiento a la UE buscando apoyo económico para el mencionado plan, presentándolo con un sesgo socio-humanitario. La ONU, además, abrió en el país andino una oficina del Alto Comisionado para los Derechos Humanos ante el aumento de las violaciones de éstos. ${ }^{17}$

Pastrana inició los contactos con las FARC en 1999 y creó una Mesa de Diálogo y un Comité Temático para debatir en Audiencias Públicas propuestas de la sociedad civil, que por fin se tomaban en consideración. En el año 2000 se fijó la agenda, priorizando el estímulo a la producción, la edu-

15 Transparency International: Índice de percepción de corrupción 2004, Transparency International, Berlin, 2004 (http://www.transparency.org/tilac/indices/indices_percepcion/2004/ cpi2004_\%20lista.pdf, consulta octubre de 2008).

16 Ver DELCOLEC: "Lanzan II Laboratorio de Paz en el sur de Colombia" [2004] (http://www.delcol.cec.eu.int/es/novedades/boletin_124.htm, consulta octubre de 2008).

17 Ver Mesa, Manuela, y Aguirre, Mariano: "Colombia y Europa: sociedad civil y proceso de paz”, en Mesa, Manuela (coord.): El papel de Europa en un futuro proceso de paz para Colombia, Centro de Investigaciones para la Paz-Fundación Hogar del Empleado (CIP-FUHEM), 2003 (separata de Papeles de Cuestiones Internacionales, 83), pág. 2, y sobre el Plan Colombia, Presidencia de la República de Colombia: Plan Colombia, Presidencia de la República de Colombia, Santa Fe de Bogotá, 1999. 
cación, la investigación, el empleo, la justicia social, la protección medioambiental y la sustitución de cultivos ilícitos. No obstante, según María del Carmen Ruedas y Carlos Clavijo, cambios en dicha agenda, una escasa definición de los escenarios y de los tiempos de discusión, el no reconocimiento por las partes de la negociación como única salida al conflicto y la exclusión práctica de la ciudadanía de la toma de decisiones hicieron fracasar el plan. ${ }^{18}$

Los países europeos y americanos acogieron con poco entusiasmo el Plan Colombia. En una reunión celebrada en Panamá en el año 2000, y en la Cumbre Iberoamericana de Jefes de Estado y Gobierno, no se logró un compromiso general. ${ }^{19}$ Por su parte la Administración española reconocía que tenía un claro sesgo policial-militarista, aunque también contenidos sociales que justificaban apoyarlo. Antonio Sanz Trillo piensa que la actitud del Partido Popular, mayoritario entonces en el Parlamento español, rompía con la posición neutral de gabinetes anteriores y comprometía la posibilidad de que la UE pudiese ejercer un papel mediador en los conflictos del país andino. ${ }^{20}$

Como expresión de la posición crítica de la UE con el Plan Colombia, la valoración que realizó el Parlamento Europeo en febrero de 2001 es muy ilustrativa:

"Considerando que el Plan Colombia no es producto de un proceso de diálogo entre los distintos actores sociales y considerando que la aceptación de la estrategias de paz por todas las instituciones del país constituiría un desarrollo deseable que debería incluir no sólo acciones para combatir la producción y el tráfico de drogas sino también una estrategia para la recuperación económica y social, el fortalecimiento de las instituciones y el desarrollo social, todo lo cual necesita ser apoyado.

18 Ruedas, María del Carmen y Clavijo, Carlos: "Consideraciones clave en el diseño de las negociaciones de paz: reflexiones para el caso colombiano", en Mesa (coord.): El papel de Europa, págs. 13-21.

19 Sobre la posición europea respecto al Plan Colombia, ver Roy, Joaquín: Europe: neither Plan Colombia, nor peace process - from good intentions to high frustrations, European Union Center, Miami (University of Miami Working Papers, 2/7), 2003 (http://www.miami.edu/EUCenter/royworkingpaper_colombia.pdf, consulta octubre de 2008), y acerca de la actitud de los países de América Latina, especialmente de los vecinos, quienes temían que el conflicto rebasara las fronteras y les implicase directamente, ver Malamud, Carlos: El complejo proceso para la paz en Colombia. Las difíciles relaciones de Colombia con sus vecinos, Real Instituto Elcano de Estudios Internacionales, Madrid (Working Paper, 26/2 003 13-10), 2003, y El complicado proceso para la paz en Colombia. Las difíciles relaciones de Colombia con sus vecinos: Venezuela, $2 .^{a}$ parte, Real Instituto Elcano de Estudios Internacionales, Madrid (Working Paper, 5/2004 3-2), 2004.

20 Sanz Trillo, Antonio: Política exterior del Partido Popular en Colombia, CIP-FUHEM, Madrid (Documento de Trabajo), 2004. 


\section{MARGARITA LILLO GONZÁLEZ Y ANTONIO SANTAMARÍA GARCÍA}

Considerando que uno de los objetivos del Plan Colombia consiste en acabar con el tráfico de drogas y la extensión de los cultivos ilegales mediante una estrategia que favorece la fumigación aérea y el uso de agentes biológicos, métodos que producen el desplazamiento forzado de familias y comunidades y que afectan gravemente la riza biodiversidad de Colombia [...].

Advierte [este Parlamento] que el Plan Colombia contiene aspectos que son contrarios a las estrategias de cooperación y proyectos ya comprometidos por la Unión Europea, y que ponen en peligro sus programas de cooperación $[\ldots]]^{\prime 21}$.

La UE definió un nuevo modelo de relaciones de Asociación Estratégica en la Primera Cumbre de Jefes de Estado y Gobierno Europeos y Latinoamericanos en 1999, basado en la consolidación democrática, el multilateralismo en política exterior frente al unipolarismo de Estados Unidos y la liberalización comercial, aunque supeditado todo al reajuste presupuestario debido a su ampliación y a lo acordado en la nueva ronda de la OMC.. ${ }^{22}$ Además en el año 2000 materializaba su respaldo a la pacificación colombiana proponiendo la creación de Laboratorios de Paz, ayudas a las reformas administrativo-judiciales y a la lucha contra la pobreza y los desplazamientos forzosos, y con un acuerdo básico de cooperación y asistencia técnico-económica y una dotación de 105.000.000 de euros hasta 2006. Con ese fin se constituía el Grupo de Apoyo al Proceso de Paz, que en sus primeras reuniones declaraba que no existían alternativas a la negociación y recomendaba adoptar políticas estructurales para mitigar las desigualdades, considerándolas causas del conflicto. En la conferencia celebrada en la ciudad de Bruselas en 2001 se formó una Mesa de Donantes o Grupo de los $24(\mathrm{G}-24)^{23}$ en la que la comunidad internacional se compro-

21 Comisión Europea: Resolución del Parlamento Europeo sobre el Plan Colombia y sobre el apoyo al proceso de paz en Colombia, Directorado General de Relaciones Exteriores (1-2), Bruselas, 2001.

22 Ver La Unión Europea y Colombia: un enfoque alternativo, CIP-FUHEM, Madrid (Documento Estratégico, octubre), 2004; Salafranca, José Ignacio: Resolución del Parlamento Europeo sobre una asociación global y una estrategia común para las relaciones entre la UE y América Latina, Parlamento Europeo, Estrasburgo [2000/2249(INI)], 2001, e Informe sobre la propuesta de Decisión del Consejo relativa a la firma de un Acuerdo de Diálogo Político y Cooperación entre la Comunidad Europea y sus Estados miembros, por una parte, y la Comunidad Andina y sus países miembros por otra parte [COM (2003) 695], CAEDHSCPD, Estrasburgo (26-2, A50119/2004), 2004, y Sanahuja, José Antonio: "Mecanismos de cooperación Europa-América Latina", Foreign Affairs en Español, 2/2, México, 2002, págs. 36-51, y "Paz, democracia y desarrollo en las relaciones UE-América Latina: el caso de Colombia”, en Mesa y Aguirre (coords.): El papel de Europa, págs. 33-37.

23 Acuerdo de los Pozos [2001] (www.ideaspaz.org/proyecto03/boletines/download/boletin03/acuerdo_los_pozos.doc, consulta octubre de 2008). 
metió a aportar otros 800.000.000 de dólares estadounidenses (más de la mitad concedidos por el gobierno de Washington). Por su parte la Comisión Europea reafirmó que no financiaría soluciones militares, aludiendo a una resolución de su Parlamento que rechazaba el supuesto del Plan Colombia de que el narcotráfico era el motivo de la violencia y también la estrategia de fumigación de los cultivos ilegales por los efectos medioambientales y los desplazamientos de personas que provoca. Apostaba, en cambio, por el fortalecimiento institucional, el diálogo, el desarrollo alternativo y la ayuda humanitaria, más acordes con el ideario europeo ${ }^{24} \mathrm{y}$ con la creencia de que las causas del conflicto había que buscarlas en las desigualdades socioestructurales. ${ }^{25}$

Conforme a los objetivos establecidos en la reunión del G-24 en 2001, la UE manifestó que reforzaría sus ayudas a la defensa de los Derechos Humanos, los desplazados y víctimas del conflicto y al afianzamiento de la sociedad civil en Colombia. Con el propósito de promocionar dicha sociedad civil y su contribución al proceso de pacificación y con el fin de acoger iniciativas de distintas organizaciones se constituyó en 1999 la Fundación Ideas para la Paz y se empezaron a celebrar en el año 2000 los Encuentros por la Paz, continuados posteriormente y sistematizados en el Acuerdo de los Pozos, ${ }^{26}$ de febrero de 2001, entre el presidente colombiano Pastrana y el comandante y miembro fundador de las FARC Manuel Marulanda, Tirofijo.

24 Ver DELCOLEC: La Unión Europea y Colombia, y "Colombia/relaciones", así como Comisión Europea: Declaración de la presidencia en nombre de la Unión Europea en la segunda reunión del Grupo de Apoyo al proceso de paz en Colombia, Directorado General de Relaciones Exteriores, Bruselas, 2000; Parlamento Europeo: European Parliament resolution on Plan Colombia \& support for the peace process in Colombia (01-02-2001), Parlamento Europeo, Estrasburgo, 2001 (www.europa.eu.int/comm/external_relations/colombia/doc/ep01_02_01.htm, consulta octubre de 2008), y Resolución del Parlamento Europeo sobre una asociación global y una estrategia común para las relaciones entre la UE y América Latina, Parlamento Europeo, Estrasburgo [2000/2249(INI)], 2000, y Jelsma, Martin: "Estrategias políticas y de cooperación de la Unión Europea en materia de lucha contra las drogas", en Seminario-taller: Balance y perspectivas de las relaciones políticas y de cooperación entre la Unión Europea y Colombia, Lleida, 2004 (14-16 de julio), págs. 48-56 (http://80.24.164.28/atelier/elobservatorioeneuropa/Documentos/ConclusionesSeminario.htm, consulta octubre de 2008).

25 Comisión Europea: Declaración de la presidencia.

26 El Grupo de los 24 está formado por: Argentina, Brasil, Canadá, Chile, Estados Unidos, Japón, México, Noruega, Suiza y los países miembros de la UE. Su órgano ejecutivo lo integran la Comisión Europea, la ONU y varios organismos multilaterales como la Corporación Andina de Fomento (CAF), el Banco Interamericano de Desarrollo (BID), el Fondo Monetario Internacional (FMI) o el Banco Mundial (BM). 


\section{Las relaciones UE-Colombia en la nueva coyuntura tras el 11-S y la guerra de Irak}

Tras los atentados del 11 de septiembre de 2001 (11-S) contra las Torres Gemelas de Nueva York, la postura dura de la Administración de Estados Unidos frente al terrorismo y el narcotráfico se reforzó. Aparte del gobierno de España, que asumió la presidencia de la Unión Europea durante el primer semestre de 2002, el Reino Unido apoyó entonces esa posición y la UE suavizó sus críticas al Plan Colombia, aunque mantuvo su actitud de desvincularse de su vertiente militar y de proseguir su propia estrategia de negociación y reformas. ${ }^{27}$ Además, en febrero de ese mismo año, inició uno de sus proyectos más emblemáticos en el país sudamericano, el Laboratorio de Paz en el Magdalena Medio, un conjunto articulado de programas para el fortalecimiento institucional, la defensa del diálogo y de los Derechos Humanos y el desarrollo alternativo, dotado con 34.800.000 euros hasta 2009 y que se extendería luego a otras regiones. También se puso en marcha el ECHO's Global Plan 2002 de acción humanitaria, financiado con otros 8.000.000 para quince meses. $^{28}$

Frente al narcotráfico la UE continuó abogando por estrategias de sustitución de siembras. Esa posición se fundamentaba en el rechazo de muchas organizaciones sociales colombianas e internacionales a las políticas de Estados Unidos al respecto, a la ausencia de estudios científicos fehacientes sobre el impacto de las fumigaciones en el medioambiente, la salud y los desplazamientos humanos y en la dispersión de los cultivos ilegales, así como en la concentración de las medidas de tolerancia cero en los productores agrícolas, no en las redes de tráfico de estupefacientes y de insumos para elaborarlos. Otro argumento más era el hecho constatado

27 Sanz Trillo, Antonio: Política exterior del Partido Popular, pág. 6. Para el discurso de apertura de la presidencia española de la Unión Europea en la primera mitad de 2002 ver Aznar, José María: Más Europa. Programa de la presidencia española de la Unión Europea (1 de enero - 30 de junio, 2002), Presidencia de la Unión Europea, Brussel [ref. NEWS02-001EN (11/1/2002)], 2002, y sobre la declaración del Parlamento Europeo acerca de Colombia, Parlamento Europeo: Resolución del Parlamento Europeo sobre Colombia, Parlamento Europes, Estrasburgo [P5TA (2002) 0129 (14/3/2002)], 2002.

28 Ver Programa de desarrollo y paz del Magdalena medio [2004] (http://www.pdpmm.org.co/ lab/intro.htm, consulta octubre de 2008), y DELCOLEC: "Lanzan II Laboratorio de Paz". 
de que la aplicación de tales políticas no había frenado el crecimiento de la oferta de narcóticos. ${ }^{29}$

Posteriormente, sin embargo, se observó un cierto alejamiento del Parlamento Europeo sobre su posición defendida en febrero de 2001 contra las fumigaciones de cultivos de drogas. En opinión de Martin Jelsma:

"Desde el 11 de septiembre [de 2001] y los atentados de Madrid [de 2004], Europa ha ido adoptando paulatinamente el discurso de la guerra contra el terrorismo e incluso su mezcla cuestionable con la guerra antidrogas [...]. En el ámbito de la declaración de intenciones, observamos que se sigue repitiendo el discurso del desarrollo alternativo, los Derechos Humanos y la construcción de la paz (como en la declaración de Londres de julio de 2003), pero suena más vacío que nunca por su falta de propuestas e iniciativas concretas que intenten desafiar el discurso actual sobre drogas y dinámicas de conflictos". ${ }^{30}$

Mientras tanto se habían suspendido las negociaciones entre el gobierno de Colombia y el ELN en 2001 y en febrero de 2002 cesaron las celebradas con las FARC. Estos hechos provocaron que la presidencia del Consejo de la Unión Europea expresara su frustración en cuanto a lo que ocurría en el país andino. ${ }^{31}$ Por idéntica razón, en cambio, Estados Unidos levantaba las restricciones a su ayuda militar a esa nación. Uribe ganaba las elecciones en mayo y presentaba su Política de Defensa y Seguridad Democrática y el Plan Patriota, una estrategia también militar, elaborada conjuntamente con la Administración norteamericana ${ }^{32}$ y destinada a derrotar por las armas a las FARC, obligándolas a replegarse y aislándolas y acorralándolas. Tras la matanza perpetrada por miembros de dicha agrupación en Bojayá, ${ }^{33}$ el Consejo de la UE la incluyó en su lista de organizaciones terroristas (junio de 2002), en la que ya estaban las AUC y que en abril de 2004 registraría además a el ELN. Esa opción había sido rechazada anteriormente para no

29 Transnational Institute: Alternative development and conflict in Colombia. Cross purposes, Transnational Institute, Ámsterdam (Debate Papers, Jaunary $7^{\text {th }}$ ), 2003.

30 Jelsma: "Estrategias políticas y de cooperación", pág. 52.

31 Ver Presidencia del Consejo de la Unión Europea: Declaración de la presidencia en nombre de la Unión Europea sobre la ruptura del proceso de paz en Colombia, Consejo de la Unión Europea, Bruselas (6555/02, presse 44, P 19/02), 2002 (22 de febrero).

32 Ver Presidencia de la República de Colombia, Ministerio de Defensa Nacional: Política de defensa y seguridad democrática, Presidencia de la República de Colombia, Ministerio de Defensa Nacional, Santa Fe de Bogotá, 2003, y CODHES: The "Patriot Plan", CODHES, Santa Fe de Bogotá, 2004 (www.codhes.org.co, consulta octubre de 2008).

33 En un enfrentamiento con las AUC en mayo de 2002, en Bojayá, un artefacto explosivo de las FARC provocó la muerte de un centenar de campesinos, la mitad de ellos niños. 
comprometer su rol mediador en el conflicto colombiano ${ }^{34}$. La diplomacia española tuvo un papel destacado en el cambio de consideración de tales grupos guerrilleros, lo que demuestra la incidencia que tiene la opinión del gobierno de Madrid en la política europea para América Latina, que en muchas ocasiones se pone en tela de juicio.

La inclusión de las FARC en su lista de organizaciones terroristas, en efecto, se acompañó de algunos cambios en la posición de la UE respecto al conflicto colombiano durante el primer trimestre de 2002, que se reflejó fundamentalmente en el tono de las declaraciones oficiales. ${ }^{35}$ Pese a ello la Unión Europea ha mantenido y manifestado explícitamente sus tesis de que las causas de los enfrentamientos civiles en el país andino son, en última instancia, la desigualdad y la pobreza, ha exigido al gobierno de Uribe respeto a los Derechos Humanos y democráticos y su adhesión sin reservas al Estatuto de la Corte Penal Internacional ${ }^{36}$ y ha seguido abogando por soluciones de diálogo y negociadas. Ahora bien, el esfuerzo comunitario por mejorar la ayuda al desarrollo en general es escaso, como ponen de relieve los apenas 250.000.000 de euros asignados a América Latina en el quinquenio 2002-2006, las restricciones a la inmigración y a la acogida de refugiados y, sobre todo, lo asimétrico e injusto de las relaciones comerciales. ${ }^{37}$ En el informe de conclusiones del Consejo de Asuntos Generales y Relaciones Exteriores de la UE en enero de 2004, los Estados miembros expresaron su voluntad de colaborar con el gobierno legítimo de Colombia, pero también se reafirmaron en que ello estaría condicionado a la marcha del proceso de paz y a la implementación de una estrategia global de desmovilización, desarticulación, desarme y reinserción social de los grupos paramilitares y de satisfacción derecho de las víctimas a saber la verdad y a obtener justicia y reparación razonable..$^{38}$

34 Presidencia del Consejo de la Unión Europea: Declaración de la presidencia en nombre de la Unión Europea con ocasión del comienzo formal del diálogo del gobierno de Colombia y los grupos paramilitares AUC, Presidencia del Consejo de la Unión Europea, Bruselas [10167/04, presse 194, P 74/04], 2004.

35 Ver, por ejemplo, Parlamento Europeo: Resolución del Parlamento Europeo.

36 Colombia firmó con Estados Unidos en septiembre de 2002 un acuerdo de conformidad sobre la exención de los soldados norteamericanos a comparecer ante la Corte Penal Internacional y la no aplicación de ciertos artículos del Derecho Internacional Humanitario en la nación andina. Ver Mesa y Aguirre: "Colombia y Europa", pág. 2.

37 Comisión Europea: Informe estratégico regional sobre América Latina. Programación 2002-2006, Comisión Europea, Bruselas, 2002.

38 Consejo de Asuntos Generales y Relaciones Exteriores de la Unión Europea: Conclusiones del Consejo sobre Colombia, Consejo de Asuntos Generales y Relaciones Exteriores de la Unión Europea, Bruselas, 2004 (36 de enero). 


\section{De Londres a Cartagena}

Como reacción a las partidas asignadas en los presupuestos colombianos al programa de Seguridad Democrática, que afectaban al gasto social, y la propuesta del presidente Uribe de reformar la Constitución, el Consejo de la UE, uniéndose a las crítica de la ONU y la OEA, declaró que esas medidas reforzaban el centralismo del poder y la arbitrariedad judicial. En contraste, en las elecciones municipales-departamentales celebradas por entonces la izquierda democrática, como en otros países de América Latina, creció sensiblemente en número de votos, indicativo de que estaba asumiendo la representación del descontento por la situación de pobreza y exclusión de la nación. ${ }^{39}$

El gobierno español, que se había comprometido a financiar el proceso de paz con la aportación de 124.000.000 de dólares, no suscritos al Plan Colombia, en el cuatrienio 2000-2003, a principios de ese último año expresó su apoyo a la política de Uribe y le ofreció ayuda militar, ${ }^{40}$ quebrantando el código de conducta de la UE sobre el envío de armas a zonas en conflicto y en las que la ONU ha constatado violaciones de los Derechos Humanos. La decisión reafirmaba el apoyo del Ejecutivo de José María Aznar a la doctrina de la Guerra Preventiva de Estados Unidos, que admite la conculcación del Derecho Internacional con la justificación de la lucha antiterrorista, como en el caso de la referida reforma constitucional en el país andino. De hecho el comisario europeo de Relaciones Exteriores, Christopher Patten, manifestaba en mayo de 2003 su preocupación por la escalada militar, las acciones contra civiles y las restricciones de libertades en esa nación, ${ }^{41}$ incluso antes del inicio efectivo del Plan Patriota, cuya primera fase comenzaba un mes después en Cundinamarca. ${ }^{42}$

En respuesta a los hechos mencionados el G-24 consensuó en su reunión de julio de 2003 la Declaración de Londres contra la reforma consti-

39 Ver La Unión Europea y Colombia, pág. 4.

40 El gobierno de España envió al de Colombia 46 tanques AXM-30, ocho aviones Mirage F1, simuladores de helicópteros Black Hawk, aviones de transporte Casa-212 y le prestó asistencia tecnológico-militar y en la capacitación para la lucha antiterrorista. Además ponía a disposición del Ejecutivo del país sudamericano dos satélites de observación y comunicación. Ver "Crisis por los Mirage", El País, Madrid, 5 de marzo de 2003, pág. 9.

41 Patten, Christopher: "Mensaje del comisario de Relaciones Exteriores al Foro UEColombia", Bogotá [12-13 de mayo de 2003] (www2.rnw.nl/rnw/es/informes/unioneuropea/otrostemasdelaue/, consulta octubre de 2008).

42 CODHES: The "Patriot Plan", pág. 7. 
tucional y la erosión de las libertades, y por el fortalecimiento del parlamentarismo, la participación y la descentralización, el diálogo y el desarrollo alternativo en Colombia. Esos conceptos, tradicionales en el ideario político de la UE, debían seguirse defendiendo mediante el mantenimiento de su posición político-diplomática, reforzando sus programas, que hasta el momento habían tenido muy poco efecto debido a su escasa financiación, y permitiendo que se desbloqueasen las negociaciones en la OMC. El gobierno de Uribe, empero, perseveraba en su estrategia. En agosto de 2003 propuso medidas para aminorar las penas judiciales a los paramilitares de las AUC, que estaban pactando su desmovilización; en diciembre empezó la segunda fase del Plan Patriota y el Congreso aprobó la modificación de la Constitución. Su reforma incluye, además de lo señalado, un estado de excepción que permite al ejército registros y detenciones sin autorización de los jueces y controlar a la población mediante empadronamientos. Finalmente, en otoño, recibió un nuevo respaldo de Bush, que firmó una Directiva Presidencial de Seguridad Nacional (Acta Patriótica) relativa al país andino y consistente en asistencia y entrenamiento técnicomilitar anti-narcoterrorista y en la promoción de los Derechos Humanos y de la economía de mercado a través de la implantación del área de Libre Comercio de las Américas (ALCA).43

Transcurridos dos años de aplicación de la política de Seguridad Democrática los problemas seguían sin resolverse. Aunque los grupos armados han optado por replegarse, mantienen su capacidad militar, incluso en 2006 las FARC iniciaron una fuerte contraofensiva. La violencia se ha agravado, con más víctimas durante la presidencia Uribe que durante el mandato de Samper (1994-1998). Si bien el gobierno colombiano afirma que se han reducido algunos tipos de delitos (secuestros, homicidios), se registra un aumento de las detenciones arbitrarias y masivas, de las torturas, ejecuciones extrajudiciales y, sobre todo, de los desplazamientos. ${ }^{44}$

Uribe ha mantenido un elevado apoyo, el mayor logrado por un presidente en la historia reciente de Colombia. Todavía en septiembre de 2008 más del 60 por ciento de la población afirma que votaría por él en una encuesta realizada para Radio Santa Fe. Hay que tener en cuenta al valorar ese dato la actual crisis económica y su efecto en la elevación de la tasa de

43 Ver Comisión Colombiana de Juristas: Colombia: en contravía; CODHES: The "Patriot Plan”, y González Bustelo y Aristizábal: Colombia. La guerra que no para, pág. 13.

44 Ver Uribe ¿Seguridad social o democrática? [2004] (www.colombia.com/informes_especiales, consulta octubre de 2008), y Comisión Colombiana de Juristas: Colombia: en contravía. 
desempleo en el país andino. Desde hace tiempo, sin embargo, esa popularidad disminuye lentamente, sobre todo desde las manifestaciones ocurridas en otoño de 2004 por los citados problemas económicos, ${ }^{45}$ y eso que entonces no habían experimentado un agravamiento como el que padecen en estos momentos debido a la recesión internacional, por lo que el descontento social ha ido en aumento. Los enfrentamientos del presidente con la Corte de Justicia y la oposición también han seguido a un ritmo creciente, no obstante ha ganado terreno con la liberación de Ingrid Betancourt y otros golpes sufridos por la guerrilla, infringidos por el ejército o fortuitos, como el fallecimiento de Tirofijo a principios de 2008. También parece que hay un cierto cansancio personal o al menos de reconocimiento de que la política nacional necesita renovación, eso si, en los individuos, no en sus prioridades, según se desprende de unas declaraciones en la Cámara de Comercio de Bogotá:

"Pienso que no debe haber perpetuación del presidente, que el país debe tener muchos
líderes. Pero sí tengo que decirles, por convicción propia, a mis compatriotas, que
hagamos una gran reflexión para comprometer a las personas que nos habrán de diri-
gir con el tema de Seguridad Democrática y con el tema de confianza inversionista
[...]. El país necesita una gran fortaleza y una gran dinámica en inversión para poder
resolver los problemas sociales". ${ }^{46}$

Uribe ha conservado también el respaldo del gobierno estadounidense, aunque se desconoce cuál será la política del nuevo ocupante de la Casa Blanca, Barack Obama. No hay que olvidar, empero, que el fundamento de ese apoyo es la consideración de Colombia como un referente en la lucha contra el terrorismo y el narcotráfico en América ${ }^{47}$ y así, pasado septiembre de 2004, el Congreso de Estados Unidos certificaba que el país andino cumplía los requisitos establecidos por la legislación norteamericana para recibir 32.500.000 de dólares de los 250.000.000 que se le habían concedido en ayuda militar. Ese certificado ha sido cuestionado por organizaciones como Washington Office on Latin America (WOLA) tras constatar que no

45 Hasta llegar al actual 64 por ciento, su popularidad se ha ido reduciendo lentamente. En septiembre de 2003 era de 80, un año después de 77 y en febrero de 2005 de 71, según las encuestas realizadas periódicamente por Invamer Gallup. Ver "Conociendo al Presidente", Dinero.com [2004] (http://www.dinero.com:8080/larevista/168/EDITORIAL.asp, consulta octubre de 2008), la noticia recogida en la revista Semana, Santa Fe de Bogotá, 2005 (24 de febrero), y "Uribe dice que no quiere perpetuarse en el poder, pero persiste apoyo popular a la reelección" [septiembre de 2008] (www.radiosantafe.com, consulta octubre de 2008).

46 "Uribe dice que no quiere".

47 Hill, James T.: Columbia: key to security in the Western Hemisphere, Heritage Foundation, Washington (Hemisphere Heritage Lectures, 790), 2003. 
se ha producido una reducción sustancial de las violaciones de los Derechos Humanos. El propio Bush ratificó luego la ayuda en una visita a Santa Fe de Bogotá en noviembre de 2004, la primera de su segundo mandato, y prometió además avanzar en las negociaciones para constituir el Tratado de Libre Comercio (TLC). ${ }^{48}$

También hay influyentes voces en Estados Unidos desde hace tiempo, no obstante lo dicho, que sobre todo tras las dificultades presentadas en la eufemísticamente llamada postguerra de Irak, abogan por mantener una postura más multilateralista en las relaciones exteriores y por la búsqueda de apoyos en Europa. La Administración norteamericana ha escuchado esas voces, sobre todo en lo referente al acercamiento a los aliados del Viejo Continente, y se esperan pasos más decididos en ambos sentidos por parte del nuevo presidente Obama. La posición de la UE hacia Colombia se ha reforzado por esas razones, tras la victoria electoral del Partido Socialista en España en 2004, repetida cuatro años después, que defiende un ideario más europeista que su antecesor, el Partido Popular, y dos de cuyas primeras decisiones de gobierno fueron la retirada de las tropas españolas de Irak y la suspensión de la entrega de armas a Colombia que acordara el Consejo de Ministros anterior, aunque manteniendo la cooperación en materia de defensa. La ONU, por otra parte, ha visto limitada la autonomía de sus representantes en la nación sudamericana desde que en 2005 concluyó la misión de su delegado James Lemoyne. ${ }^{49}$

Luces y sombras, por tanto, definen el panorama de los últimos años. Se han reabierto negociaciones con el ELN, pero los acuerdos con la AUC están siendo cuestionados por el temor a una amnistía que exculpe a sus integrantes y les reconozca derechos sobre las propiedades conseguidas gracias a la violencia y al narcotráfico..$^{50}$ Por otra parte la Corte Consti-

48 Ver Isacson, Adam: Was failure avoidable? Learning from Colombian peace process, D. B. Fascell North South Center, Coral Gables (Working Paper, 14), 2003 (http://www.miami.edu/nsc/publications/NSCPublicationsIndex.html, consulta octubre de 2008), y "Visita del presidente George W. Bush a Colombia, Cartagena de Indias, 21 de noviembre de 2004", en CIP-FUHEM: Boletín Electrónico, 2 del Proyecto Europa y Colombia: Diplomacia y Sociedad Civil, Madrid [2004] (www.euro-colombia.org, consulta octubre de 2008). Para los discursos pronunciados por Bush y Uribe durante esa visita, ver también la página web de la Presidencia del Gobierno de Colombia (http://cne.presidencia.gov.co, consulta octubre de 2008).

49 "La ONU retira sus buenos oficios en Colombia y no buscará un sustituto a su asesor especial James Lemoyne", Europa Press [23 de enero de 2005] (http://www.lukor.com/not-mun/america/0501/23150640.htm, consulta octubre de 2008)".

50 Vivanco, José Miguel: "La desmovilización de las Autodefensas Unidas de Colombia (AUC) y los desafíos planteados" [2004] (www.vivalaciudadania.org/cajas/caja99/caja.htm, consulta octubre de 2008). 
tucional declaró ilegal la reforma de la Carta Magna pretendida por Uribe, con protestas de su gobierno, pero con el respaldo de la ONU y de muchas organizaciones nacionales e internacionales..$^{51}$ Además el cerco a las FARC les ha desplazado a las fronteras, con el peligro de regionalización del conflicto, de lo que se quejaron en sucesivas ocasiones, como en las cumbres de la Comunidad Andina, los embajadores de los países vecinos. La reciente incursión del ejército colombiano en territorio de Ecuador para detener a guerrilleros ha confirmado ese temor.

El presidente de Venezuela, Hugo Chávez, que también ha expresado el mismo temor por la regionalización del conflicto, se ha comprometido en varias ocasiones a no apoyar a los grupos armados de Colombia, pero su posición real es ambigua. Se ha ofrecido como mediador y al tiempo hay sospechas de que no ha cesado su respaldo a actividades contra el gobierno del vecino país. Hechos como la violación de las fronteras ecuatorianas, con antecedentes hace unos años al denunciarse que un jefe guerrillero fue detenido por tropas colombianas en suelo venezolano, así como el avance del libre comercio en la región y los entresijos de las relaciones económicas y políticas de las diferentes naciones del área con la Unión Europea y Estados Unidos, dificultan además la débil integración andina, que de por sí progresa lentamente debido a los desequilibrios e inestabilidad socio-política. ${ }^{52}$

Aparte de los vecinos, otros Estados de América han expresado reiteradamente sus reticencias frente a ciertas propuestas del gobierno colombiano. Así, por ejemplo, en la VI Conferencia de Ministros de Defensa de las Américas rechazaron la iniciativa de Uribe de crear una fuerza conjunta para combatir el narco-terrorismo y elaborar una lista de

51 Ver Ruedas, María del Carmen: "Paradojas y contradicciones en Colombia", Anuario CIP, Madrid, 2004, págs. 197-198, y Comisión Colombiana de Juristas: Colombia: en contravía, págs. 61-64.

52 Ver "Cumbre Presidencial Colombia-Venezuela, Cartagena de Indias, Colombia, 9 de noviembre de 2004", en CIP-FUHEM: Boletín Electrónico, 0 del Proyecto Europa y Colombia: Diplomacia y Sociedad Civil, Madrid [2004] (www.euro-colombia.org, consulta octubre de 2008), pág. 2; "Colombia y las negociaciones del Tratado de Libre Comercio", en CIP-FUHEM: Boletín Electrónico, 2, pág. 1; Carvajal, Leonardo, y Pardo, Rodrigo: "La internacionalización del conflicto doméstico y los procesos de paz (historia reciente y principales desafios)", en Ardila, Martha; Cardona, Diego et al. (eds.): Prioridades y desafíos de la política exterior colombiana, Fiedrich Ebert StiftungHanns Seidel Stiftung, Santa Fe de Bogotá, 2002, págs. 197-216; International Crisis Group: Guerra y droga en Colombia, monográfico de Informe sobre América Latina, 11, Bruselas, 2004, y Hernández, Clodovaldo: "Uribe viaja a Venezuela para intentar cerrar la crisis diplomática", El País, Madrid, 2 de abril de 2005, pág. 9. 
organizaciones ilegales, aunque al mismo tiempo declararon el apoyo a sus políticas. ${ }^{53}$

En el mes de julio de 2004, durante la celebración del aniversario de la Declaración de Londres y con una nutrida representación oficial y de organizaciones sociales, empresariales y académicas, se insistió en la pertinencia de mantenerse y avanzar en sus principios. Además, ante el inicio de la desmovilización de las AUC, la Presidencia de la Unión Europea volvió a manifestar su apoyo a soluciones negociadas — no militares - al conflicto colombiano y su preocupación por los Derechos Humanos, ${ }^{54}$ y anunció que se iniciaban los trabajos de preparación de un documento que sirviese de base para revisar la política actual, al que diversas asociaciones civiles presentaron sugerencias. ${ }^{55}$

En respuesta a las reiteradas demandas internacionales, durante la reunión de la Mesa de Coordinación y Cooperación Internacional para Colombia, celebrada en Cartagena de Indias los días 3 y 4 de febrero de 2005, Uribe reiteró que el país sufría ataques terroristas, no un conflicto armado, y reclamó un aumento de las ayudas, que el año anterior sumaron 422.000.000 de euros, y apoyo para la desmovilización de las AUC, asegurando que habría un marco legal que impedirá su impunidad, como solicitó la Comisión Europea para comprometerse en el proceso. El objetivo de la citada reunión era evaluar el cumplimiento de los compromisos adquiridos por el gobierno del país andino en la Declaración de Londres, incluidas las recomendaciones de la ONU en materia de Derechos Humanos. El Ejecutivo colombiano ofreció datos sobre la reducción de las violaciones de esos derechos y de algunos delitos, como los secuestros y homicidios. Sin embargo varias organizaciones civiles alegaron en contra en un documento que, pese a ello, la situación seguía siendo dramática, reiterando de

53 Ver Grupo de los 24 (G-24): Declaración de Londres [2003] (www.actualidad colombiana.org/archivo/otros/c.doc, consulta octubre de 2008) y para una crítica a la misma, Washington Office on Latin America: "VI Conferencia de Ministros de Defensa: Un Paso Más en la Dirección Errada" [2004] (www.wola.org/military/def_ministerial_release_span_111904.htm, consulta octubre de 2008).

54 Ver "Reunión de Colombia en Londres, Chatham House (12-06-2004)", en La Unión Europea y Colombia, pág. 2, y Presidencia de la Unión Europea: Declaración de la presidencia en nombre de la Unión Europea con ocasión del comienzo formal del diálogo del gobierno de Colombia y los grupos paramilitares AUC, Presidencia de la Unión Europea, Bruselas [10167/04, presse 194. P 74/04], 2004 (http://europa.eu.int/comm/external_relations/colombia/doc/decl_300604_es.pdf, consulta octubre de 2008).

55 CODHES: Recomendaciones sobre Colombia a la presidencia holandesa de la UE, CODHES, Santa Fe de Bogotá, 2004. 
nuevo la Declaración de Londres como precepto para la colaboración internacional en su solución. ${ }^{56}$ Según esas organizaciones, por ejemplo, los desplazados forzosos habían aumentado en 2004 un 38,5 por ciento respecto al año anterior ${ }^{57} \mathrm{y}$, en general, aunque se reconocían las mejoras referidas por el gobierno, éstas eran insuficientes para valorar el panorama como positivo.

Si bien en la reunión de Cartagena la UE volvió a insistir en los términos recogidos en la Declaración de Londres sobre las condiciones para ayudar en el proceso de desmovilización de las AUC y en la solución del conflicto colombiano en general, en la declaración final se observa un cierto deslizamiento hacia la posición oficial de Uribe. Por ejemplo se eliminaron de ella términos como "conflicto" o "crisis humanitaria", que estaban en dicha declaración pero cuya aplicación a la situación del país andino ha negado reiteradamente su gobierno. ${ }^{58}$

Respecto de las negociaciones con los paramilitares, y a pesar de las promesas del Ejecutivo colombiano, se han desarrollado sin un marco legal específico y adecuado. Su elaboración había sido uno de los compromisos de la Declaración de Londres, adquirido por Uribe y reiterado en la reunión de Cartagena, junto con la promesa de erradicar el paramilitarismo, un fenómeno fuertemente arraigado en la nación sudamericana. ${ }^{59}$

\section{Comercio y cooperación Colombia-Unión Europea}

La UE es el mayor exportador e importador mundial de mercancías. Los productos latinoamericanos, aunque han aumentado su participación en ese comercio últimamente, representan poco más de un 5,5 por ciento en el importe de las compras europeas en el exterior. Colombia es el séptimo país de la región que más bienes envía al mercado del Viejo Continente, que en su conjunto es el segundo receptor más importante de los mismos tras el de Estados Unidos, superando a la Comunidad Andina y Venezuela, que antes de 2006 ocupaban esa posición.

56 Lozano, Pilar: "Colombia pide a las ONG que se impliquen en el plan para desmovilizar a los paramilitares”, El País, Madrid, 2 de abril de 2005, pág. 9.

57 CODHES: III Seminario.

58 Declaración de Cartagena [2005] (http://www.presidencia.gov.co/sne/2005/febrero/ 03/15032005.htm, consulta octubre de 2008).

59 Human Rigths Watch: Colombia: Librando a los paramilitares de sus responsabilidades, Human Rigths Watch, Washington, 2005 (Documento Informativo, enero). 
Si descendemos al nivel de los países europeos, naciones como Holanda, España — que ha pasado recientemente del sexto al segundo lugar entre las del Viejo Continente-, Italia o Alemania están entre los diez principales socios comerciales de Colombia. A los dos primeros es donde se dirigen más exportaciones del país andino, mientras que es en Alemania y luego en España donde éste compra más.

La importancia del mercado europeo en su conjunto, además, ha crecido recientemente para Colombia, incluso ha mejorado su balanza comercial con él, que hasta hace poco era deficitaria, pero que desde 2003 arroja un saldo positivo. No se ha logrado, sin embargo, su apertura en grado suficiente para exportaciones no tradicionales y con alto valor añadido. ${ }^{60}$

Los datos anteriores y otros, como por ejemplo las más de 1.600 empresas de Colombia que realizan negocios con países de la Unión Europea en los inicios de este nuevo milenio, número que, además, ha registrado un crecimiento de más del 20 por ciento en algunos años, ${ }^{61}$ evidencian la importancia del mercado y de la política comercial y económica europeos para la nación sudamericana. A ello hay que añadir, además, su relevancia como instrumento prioritario para el fomento del desarrollo, la ayuda efectiva a erradicar la pobreza, mitigar las desigualdades y sus efectos: violencia, conflicto armado, terrorismo o narcotráfico, así como para colaborar a reemplazar los cultivos ilegales y, en fin, a sentar las bases de una paz negociada y duradera.

Las relaciones comerciales y de cooperación entre la UE y Colombia, sin embargo, no siempre han sido suficientemente constantes ni coherentes con los problemas del país sudamericano. Además deben ser analizadas en el marco general de las relaciones europeas con la región andina.

60 En 2006 el flujo total de ese comercio fue de 6.339.000.000 de euros. Las importaciones de Colombia representaron 2.776.000.000, mientras que sus exportaciones generaron 3.575.000.000. El 32 por ciento del valor de las mercancías enviadas a Europa por el país andino es generado por el carbón, entre un 10 y un 16 por ciento reportan el banano, el café y ferroniquel y algo más de un tres por ciento la pesca y las flores. Todos ellos son productos, por tanto, con muy poco valor añadido. DELCOLEC: "Las relaciones comerciales UE-Colombia" [2008] (http://www.delcol.ec.europa.eu/es/ ue_colombia/relaciones_economicas 2.htm, consulta octubre de 2008).

61 Ver Evolución de las Relaciones Comerciales Colombia-UE. Comisión Europea, Bruselas, 2001; Fajardo, Flor Marina, y Vacca, Paola: "Europa: Un mercado de oportunidades" [2004] (http://www.proexport.com.co/VBeContent/NewsDetail.asp?ID=3122\&IDCompany=1, consulta octubre de 2008); Exportar. Acuerdos suscritos por Colombia [2004] (http://www.businesscol.com/ comex/exporconv.htm, consulta octubre de 2008); DELCOLEC: La Unión Europea y Colombia, y en general la información contenida en las páginas web www.proexport.com.co y www.businesscol.com (consulta octubre de 2008). 
En 1983 la Unión Europea y la Comunidad Andina firmaron un tratado no preferencial que fue ampliado en 1993 con un Acuerdo Marco de Cooperación o acuerdo de tercera generación que, como todos los de este tipo suscritos por la UE y países de América Latina (Argentina, Chile, Uruguay, México, Paraguay, Brasil o región centroamericana), se caracteriza por la inclusión de una cláusula democrática. La legislación comunitaria estipula el derecho a suspender unilateralmente los compromisos y programas de cooperación si se produce un retroceso en el Estado de Derecho y las libertades, cláusula que sólo está ausente en el pacto firmado con el gobierno mexicano.

Otra de las características de los llamados acuerdos de tercera generación es la inclusión en ellos de un compromiso evolutivo según el cual las partes signatarias pueden ampliar los ámbitos de cooperación establecidos en los convenios originarios. Finalmente definen también esa cooperación de manera avanzada, es decir, estableciendo o previendo que se complemente la asistencia tradicional — ayuda al desarrollo destinada a las naciones o a la población más pobres-, con medidas y acciones encaminadas a impulsar la colaboración económica, industrial, científico-técnica y medioambiental. ${ }^{62}$

En octubre de 1990 el Consejo Europeo aprobó una comunicación de la Comisión de la UE por la que se destinaban 60.000 .000 de euros a la cooperación económica con Colombia y la ayuda al desarrollo de ese país durante los cuatro años siguientes. Dicho comunicado no era sino el refrendo comunitario a una iniciativa presentada por el presidente de la nación andina, Virgilio Barco, que proponía hacer frente a las causas del narcotráfico en su sociedad. El respaldo que el gobierno de Bruselas daba a esa iniciativa se encuadró en el marco del Sistema de Preferencias Generalizadas (SPG) al derecho de exportación sin aranceles para una serie de productos durante cuatro años, prorrogado a otros diez en 1994, y de nuevo, en diciembre de 2003, hasta $2005 .{ }^{63}$

El SGP, otorgado no sólo a Colombia, sino a toda la Comunidad Andina, mejoró la situación previa, pero sigue siendo un régimen temporal y extraordinario y excluye productos muy importantes en las exportaciones

62 Arenal, Celestino del: "Los acuerdos de cooperación entre la Unión Europea y América Latina (1971-1997): evolución, balance y perspectivas”, Revista Española de Desarrollo y Cooperación, 1, Madrid, 1997, págs. 111-138.

63 DELCOLEC: La Unión Europea y Colombia. 
de la región como los plátanos. En este caso específico la llamada guerra del banano terminó con un acuerdo que, sin resolverla, ofrecía más certidumbre a los productores y comerciantes. ${ }^{64}$ Además ese sistema de preferencia fue denunciado ante la OMC por su incompatibilidad con los principios de nación más favorecida, y se obtuvo de tal organización un dictamen que consideraba que no correspondía a criterios objetivos y transparentes que permitieran a otros países en desarrollo acceder a sus beneficios. Como consecuencia de ello, y ante la necesidad de redefinir ese sistema para después de 2005, cuando concluía su prórroga, la UE comenzó a preparar otro nuevo, conocido como $\mathrm{SPG}+$, compatible con las normas de la OMC, con la previsión de que alcanzase hasta 2008, pero que finalmente durará hasta 2015. ${ }^{65}$

Actualmente están abiertas negociaciones con la Comunidad Andina para mejorar las relaciones de esa región con la UE en el marco proporcionado por el SGP+. Las partes comenzaron a hablar en 2006 y en 2008 se acaba de celebrar una tercera reunión al respecto. El objetivo es que la consolidación del sistema vigente permita pasar de un régimen unilateral y temporal a otro bilateral, más estable y duradero, corrija las asimetrías existentes y abra nuevos espacios de mercado y para las inversiones. ${ }^{66}$ Europa pretende también con ello consolidar su papel en estas últimas. Colombia concretamente es el quinto mayor receptor de esas inversiones directas del Viejo Continente en América Latina. ${ }^{67}$

En la Cumbre de Jefes de Estado y Gobierno Europeos y Latinoamericanos celebrada en Madrid en mayo de 2002, la UE reafirmó su voluntad de establecer convenios de Asociación Estratégica con los países del otro lado del Atlántico. En la práctica, además, era a los de las regiones andina y centroamericana a quienes iban a ir dirigidos esos acuerdos, pero sus representantes no lograron que en las conclusiones de la reunión se

64 Ver Declaración (2002).

65 DELCOLEC: "Las relaciones comerciales". Sobre el proceso de reforma del SGP ver Comisión Europea: Communication from the Commission to the Council, the European Parliament and the European Economic and Social Committee, Comisión Europea, Bruselas [COM (2004) 461 final, 7:7], 2004.

66 Ver Comunidad Andina: http://www.comunidadandina.org/exterior/can_ue.htm (consulta octubre de 2008).

67 Las inversiones directas de la UE descendieron de 10.240.000.000 dólares en 2005 a 6.423.000.000 en 2006, pero aún así ambas cifras son las más altas registradas desde 1994. Los sectores que reciben principalmente esos recursos son el petrolero (28 por ciento), otras actividades mineras (28 por ciento también), y las comunicaciones y servicios, DELCOLEC: "Las relaciones comerciales". 
incluyesen compromisos para establecer un área franca de comercio y apenas se consiguió avanzar en el problema del libre intercambio de productos, supeditando el tema, como suele ser costumbre, a la finalización de la ronda de la OMC y a la reforma de la Política Agraria Común. ${ }^{68}$ Las perspectivas de unas relaciones mercantiles más abiertas, por tanto, no eran nada halagüeñas.

En la cumbre de mayo de 2004 entre la Unión Europea y América Latina, celebrada en Guadalajara, la posibilidad de que la primera iniciase nuevas negociaciones con la Comunidad Andina se supeditaron, de nuevo, a los avances en la integración de la región y a la conclusión de la ronda de la OMC, que al fin sucedió en diciembre de ese año, pero con compromisos sobre liberalización comercial muy limitados por la escasa reforma de la Política Agraria Común.

La reunión de Guadalajara, por otra parte, reafirmó la voluntad multilateralista de las partes y su apoyo a las soluciones negociadas de los conflictos, aunque omitiendo hacer mención expresa a Colombia en las conclusiones finales por presiones de su gobierno, que declaró su esperanza en que Europa redujese sus presiones contra las políticas puestas en marcha, aumentase su ayuda y la subordinase a la estrategia de seguridad del presidente Uribe. Además la concentración de los recursos de la UE en su estrategia de ampliación y de reforzar la política de buena vecindad con sus países fronterizos, aumentó el temor a que los de América Latina perdiesen aún más posiciones entre las prioridades de la política exterior comunitaria. ${ }^{69}$

En el ámbito de la cooperación para el desarrollo, el Acuerdo sobre Cooperación y Diálogo Político firmado en 2003 entre los representantes europeos y los de la Comunidad Andina, y que sustituía al anterior Acuerdo Marco Regional sobre Cooperación de 1993, rige las relaciones con los países de esa región sudamericana. En el caso concreto de Colombia, aunque está sujeto a lo suscrito en dicho convenio, existe también un documento guía, Estrategia-país 2002-2006, ${ }^{70}$ que fue modificado para extenderse al período 2015. Dicha cooperación se destina a tres objetivos fundamentales: el apoyo a los procesos de paz, a las estrategias

68 Ver Romero Rodríguez, José J.: Los efectos de la Política Agraria Europea. Un análisis crítico, Desclee de Brouwer e Interpón, Bilbao, 2002; Sanahuja, "Paz, democracia", págs. 33-37, y Salafranca, Informe sobre la propuesta.

69 DELCOLEC: La Unión Europea y Colombia.

70 Comisión Europea: Colombia. Country strategy paper, Comisión Europea, Bruselas, 2002. 
que permitan enfrentar las causas del conflicto y a socorrer a sus víctimas. $^{71}$

Hasta 1984 Colombia no se había beneficiado prácticamente de la ayuda europea. Entre 1979 y 1989 recibió una aportación de 28.500.000 euros, y en quinquenio siguiente (1990-1994) esa cifra aumentó hasta 87.000.000. La UE, sumando la aportación común y la de sus países miembros, proporciona a la nación andina más de la mitad del dinero oficial que ingresa destinado a cooperación para el desarrollo. En los últimos años España se ha convertido en el Estado que más aporta. ${ }^{72}$

El referido documento Estrategia-país 2007-2013, que programa ayudas de la UE para terceros países, asigna a Colombia en los años en que estará en vigor 160.000.000 de euros y prioriza que se destinen a mejorar la productividad y competitividad de su economía y su comercio, el desarrollo alternativo y sostenible, la paz y estabilidad socio-política y la promoción del Estado de Derecho, los Derechos Humanos y la justicia. $^{73}$

Las cifras anteriores significan que la UE es el primer donante internacional de ayuda al desarrollo para Colombia, pero también que los recursos asignados son insuficientes. Aparte de aumentar su cuantía, han de enfocarse aún más a fomentar los Derechos Humanos y democráticos, a aminorar las desigualdades sociales y la pobreza, a incentivar la construcción de la Comunidad Andina, sobre todo avanzando en la negociación de un Acuerdo de Asociación Estratégica y en la liberalización del comercio. Hasta hace unos años la Ayuda Oficial al Desarrollo (AOD) europea se dirigía hacia la educación y la cultura, el fortalecimiento institucional, el desarrollo social y económico y el medio ambiente. Últimamente, como consecuencia de la agudización del conflicto armado, se presta especial atención a socorrer a la población víctima de los desplazamientos internos que éste provoca y la lucha contra sus causas, manteniendo el objetivo prioritario de la defensa de los Derechos Humanos. ${ }^{74}$

71 Ver la página web de DELCOLEC: http://www.delcol.cec.eu.int/es/novedades/FINAL\% 20FINAL\%20CONCEPT\%20NOTE.doc (consulta octubre de 2008).

72 Banco Interamericano de Desarrollo: Colombia. Informe sobre Coordinación de Donantes, Banco Interamericano de Desarrollo, Washington, 2003, pág. 45.

73 DELCOLEC: "Cooperación en materia económica y comercial" [2008] (http://www.delcol.ec.europa.eu/es/ue_colombia/relaciones_economicas3.htm, consulta octubre de 2008).

74 DELCOLEC: "Relaciones UE y Ecuador" [2005] (http://www.delcol.cec.eu.int/es/ue_ecuador/relaciones.htm, consulta octubre de 2008), y "Cooperación en materia". 
Un aspecto importante de la cooperación europea en el país andino, y que representa una diferencia sustancial respecto de la de Estados Unidos, es que ha mantenido su independencia y alejamiento del Plan Colombia al centrarse en contribuir a superar las causas del conflicto y sus efectos sobre la población. Así, por ejemplo, en la tercera reunión del Grupo de Apoyo al Proceso de Paz, celebrada en Bruselas el 30 0de abril de 2000, la UE presentó un paquete de ayudas a dicho proceso de aproximadamente 330.000 .000 de euros.

La ayuda de la UE a Colombia, además, se canaliza a través de programas de cooperación bilateral entre los países comunitarios y el gobierno del país andino, de los acuerdos entre él y la Comisión Europea y de las aportaciones a organismos multilaterales para realizar acciones concretas en la nación sudamericana, a las iniciativas y actividades de las ONG y a los proyectos de cooperación descentralizada. ${ }^{75}$

Un ejemplo de lo que decimos es la cooperación ejecutada desde la Comisión Europea, que tiene como mecanismos acciones programables y no programables. Entre las primeras, tanto financieras y técnicas como económicas, se inscriben los Laboratorios de Paz, cuyos objetivos son apoyar sobre el terreno la ejecución de los acuerdos entre las partes en conflicto, construir zonas de coexistencia reforzando las instituciones locales y a los actores civiles comprometidos, y el fortalecer el desarrollo económicosocial alternativo y autosostenible. ${ }^{76}$ Hay laboratorios en el Magdalena medio, el oriente de Antioquia, el norte de Santander o el Macizo Colombiano-Alto Patía (Nariño y Cauca). Entre las acciones no programables destacan los proyectos destinados a socorrer a los desplazados. En marzo de 2005 se aprobó un plan global de asistencia para ellos. ECHO canaliza esas ayudas que ascienden a 12.000 .000 de euros y priorizan la atención a situaciones de emergencia, a la mejora del nivel de vida de las víctimas y a apoyarles para que regresen a sus lugares de procedencia. Además da prioridad a los niños y a tratar de evitar que sean reclutados por los grupos armados, así como a la coordinación entre las agencias humanitarias nacionales e internacionales, y a los 70.000 refugiados colombianos que se calcula hay en Ecuador y Venezuela. ${ }^{77}$

75 DELCOLEC: Evolución de las relaciones, pág. 23.

76 Los objetivos de los laboratorios fueron expuestos a la sociedad colombiana y a la comunidad internacional por el ex-comisionado de relaciones internacionales de la UE: Patten, Christopher: Colombia: un compromiso internacional para la paz, SPEECH, Bruselas (SPEECH/01/192), 2001.

77 Comisión Europea: Commission agrees $€ 12$ million of humanitarian assistance for victims of the internal conflict in Colombia, Comisión Europea, Bruselas (IP/05/276, 10 mar.), 2005. 


\section{Allegro ma non troppo}

En las Conclusiones del Consejo Europeo de enero de 2004, reiteradas en diciembre del mismo año, la UE volvió a mostrar sus disposición a promover una estrategia global de paz en Colombia. Esas intenciones deberían ir acompañadas de una política decidida a afrontar los problemas socio-estructurales que aquejan al país y que son los causantes del conflicto armado, la violencia en general y un caldo de cultivo idóneo para el narcotráfico. Una política, por tanto, global y dirigida a solucionar una situación extremadamente compleja y en la que intervienen múltiples factores de manera interrelacionada. Una política, a su vez, diferenciada de la que plantea el gobierno de Estados Unidos, aunque al mismo tiempo complementaria y en diálogo y cooperación con ella, pues además puede aportarle salida a los inconvenientes que ha generado su posición unilateralista y beligerante en los últimos años. Tal cooperación y diálogo, por supuesto, debe seguir extendiéndose — en este caso se trata de una práctica mucho más común y sencilla - a los principales organismos internacionales (ONU, OMC), a las ONG y a la sociedad civil en su conjunto. Una propuesta así resolvería a la vez problemas que afectan a terceros países y a los europeos - la lucha contra el narcotráfico y el terrorismo - y ayudaría a consolidar la política exterior y de cooperación común, con el consiguiente efecto positivo que ello tendría en el proceso de construcción de la UE y en el reforzamiento de su proyección e influencia mundial.

El caso colombiano, por la gravedad y duración de sus problemas, la especial combinación de factores que los explican y sus múltiples implicaciones, que además rebasan lo local y lo regional — trasnacionalización del conflicto, narcotráfico-, ha sido objeto de atención especial por parte de la UE, pero también de diferencias en su seno acerca de las estrategias que debían seguirse y de su actualización y redefinición de acuerdo con los acontecimientos y con la actitud de los aliados, especialmente de Estados Unidos. Tales problemas, sin embargo, son inherentes a las dificultades de un proyecto de integración y construcción como el europeo, todavía no solamente incipiente, a pesar de sus avances, sino además en expansión (ampliación) a nuevos países.

La definición de un ideario común en la política exterior de la UE, a pesar de las dificultades con que tropieza al contrastar con los propios de los Estados miembros y también con sus actuaciones, ha logrado avances sus- 
tanciales. Siempre es posible observarlos desde el ángulo opuesto, es decir, enfatizando sus carencias y dolencias, pero es tan poco común como necesario y, sobre todo, coherente con las circunstancias de la construcción europea, insistir en las fortalezas. Aunque sólo sea por eso las destacamos aquí.

En los términos descritos, el mantenimiento de una posición europea que fomente el diálogo y los Derechos Humanos y democráticos, basada en un diagnóstico que considera profundas y complejas las causas de los problemas colombianos (desigualdad y pobreza) y sus manifestaciones y problemas asociados (violencia, narcotráfico), debe considerarse un síntoma de consistencia y no sólo de debilidad. Ha subsistido, además, a acontecimientos como el 11-S y a las presiones de Estados Unidos ${ }^{78}$ y de algunos socios comunitarios, como Gran Bretaña o España. El caso español es especialmente significativo, pues pone de relieve que las disensiones europeas radican en ocasiones en las propias discrepancias internas de la clase política de los países. Así, mientras el Partido Popular ejerció el gobierno en Madrid, se prefirió la alineación con las posiciones unilateralistas y militaristas defendidas por la Administración republicana norteamericana, pero al ganar el Partido Socialista las elecciones de 2004, se retornó a posturas sostenidas por otros socios de la UE, Francia y Alemania particularmente, más coherentes con la tradición nacional y conformes al referido ideario europeo, según se ha expresado en sus distintas declaraciones oficiales y consensuadas a lo largo del tiempo.

Desde el punto de vista enunciado el principal problema, frente a lo que sostienen una mayoría de los análisis, excesivamente centrados en los aspectos puramente políticos ${ }^{79}$ son los soportes económicos y legales de la posición de la UE, más que su ideario y las disensiones en torno al mismo.

78 Por ejemplo en las conclusiones de una audiencia en el Subcomité para el Hemisferio Occidental del Congreso de Estados Unidos sobre el papel de la UE en Colombia, celebrada en noviembre de 2004, la mayoría republicana del Parlamento norteamericano reconocía la preocupación europea por la situación en el país andino y su ayuda para resolver los problemas, pero al mismo tiempo cuestionaba la debilidad de su compromiso en la lucha contra el narcoterrorismo. Ver Center for International Policy: Colombian programm [2004] (www.ciponline.org/colombia/hearings.htm, consulta octubre de 2008), y "Ayuda a Colombia - el papel europeo en la lucha contra el narcoterrorismo. Audiencia en el Congreso de Estados Unidos (18 de noviembre de 2004)", en CIP-FUHEM: Boletín Electrónico, 2 del Proyecto Europa y Colombia: Diplomacia y Sociedad Civil, Madrid [2004] (www.euro-colombia.org, consulta octubre de 2008), pág. 2.

79 Ver Cepeda Ulloa, Fernando: ¿Existe una política de la Unión Europea hacia Colombia? [2002] (www.com-univ-colombia.org/colloques/ponencias/cepeda.pdf, consulta octubre de 2009), y París Rojas, Rodrigo: ¿Unión Europea y Plan Colombia: Éxito o fracaso de un sueño?, OPEE, Barcelona (Working Paper, 22), 2002 (http://selene.uab.es/_cs_iuee/catala/obs/Working\%20Papers/ wp222002.pdf, consulta octubre de 2008). 
En primer lugar es preciso un notable incremento de la cooperación europea y en particular de la destinada a facilitar una salida negociada y pacífica al conflicto. Los recursos dedicados hasta ahora son insuficientes y han impedido que los proyectos de Laboratorios de Paz, auxilio humanitario, lucha contra la desigualdad y la pobreza, promoción de la sociedad civil, reforma institucional y actividades productivas sostenibles y sustitutivas de los cultivos ilegales, hayan dado frutos rápidos y consistentes con los que probar y defender su idoneidad frente a las soluciones militares y los programas de fumigación. Las cantidades asignadas deberían aumentar sustancialmente sólo para aproximarse a las aportadas por Estados Unidos, más concentradas en la financiación del Plan Patriota. ${ }^{80}$

En la lucha contra una de las lacras que afectan de forma dramática a las sociedades europeas, como el narcotráfico, la UE debería incentivar medidas dirigidas a fomentar el desarrollo alternativo, conjuntamente con acuerdos que faciliten la entrada de más productos colombianos y con más valor añadido en el mercado europeo.

En necesario también establecer requisitos más precisos en la condicionalidad de las ayudas que impidan discusiones continuas acerca de si son o no adecuadas y suficientes las medidas de determinados gobiernos en la protección y salvaguarda de los Derechos Humanos y democráticos. Así se evitarían algunas de las disensiones en el seno de la UE, como las manifestadas en torno al contenido social de los planes Colombia y Patriota o a las declaraciones de Uribe respecto al cumplimiento de los compromisos de su gobierno con esos derechos. Por ejemplo la exigencia de que éste retire la reserva al Estatuto de la Corte Penal Internacional, acate la resolución del Tribunal Constitucional colombiano que anula su reforma constitucional, cumpla los preceptos de la Declaración de Londres, que firmó, las recomendaciones de la ONU incluidas en ella, y consensúe con los organismos nacionales e internacionales competentes el marco legal para la desmovilización de las AUC. En este aspecto la UE debe incidir en la exigencia de una legislación que garantice el derecho de las víctimas del conflicto a la conocer la verdad y a obtener justicia y reparación razonable, y por lo que el Ejecutivo colombiano garantizó que velaría en la Declaración de Cartagena.

Cumplir el requisito anterior evitaría que, por falta de una definición clara, gobiernos como el del Partido Popular en España apoyasen en su

80 Banco Interamericano de Desarrollo: Colombia. Informe sobre Coordinación. 
momento el Plan Patriota colombiano, incluso justificasen el envío de ayuda militar argumentando que sus contenidos sociales lo merecían. En ese sentido sería necesario por parte de la UE el desarrollo de esos aspectos en su nunca concluido tratado constitucional por problemas en su aprobación, sancionando el código de conducta seguido hasta ahora y estableciendo luego protocolos claros de actuación.

Por último, y se ha dejado para acabar por ser lo más importante, mantener una política exterior creíble de ayuda al desarrollo requiere desbloquear urgentemente y mediante un compromiso duradero las negociaciones en la OMC en materia de liberalización del comercio y apertura de los mercados de los países más ricos. Una política con esas prioridades se debería acompañar, además, de medidas de capacitación técnico-económica, promoción de la producción sostenible, respeto al medio-ambiente y fomento de la educación, la ciencia y la investigación, que hasta ahora han sido también insuficientes y, sobre todo, se han dotado de presupuestos muy escasos.

El conflicto colombiano, en suma, se presenta como una oportunidad para el desarrollo de una auténtica política exterior europea. En la UE, y en particular en los asuntos referidos a América Latina, España ejerce un papel importante que no se debe minusvalorar. Un papel, por cierto, reconocido por sus socios comunitarios. En otras palabras, las aportaciones procedentes de ese país sobre los problemas latinoamericanos tienen un peso considerable en las decisiones que emanan del consenso de dichos socios. Por esa razón desde el gobierno, sin olvidar que su obligación es representar a todos los ciudadanos, se debería ofrecer un discurso firme y consecuente - acompañado de hechos en el mismo sentido- con la solución pacífica del referido conflicto y sin caer más en la tentación de asumir discursos y posiciones de otros de manera acrítica, aunque buscando recompensa, sobre todo si éstas se han mostrado ineficaces y hasta contraproducentes. 